\title{
Changes Over Time in HIV Prevalence and Sexual Behaviour Among Young Female Sex-Workers in 14 Sites in Zimbabwe, 2013-2016
}

\author{
Sungai T. Chabata ${ }^{1}$ (1) $\cdot$ Bernadette Hensen ${ }^{2} \cdot$ Tarisai Chiyaka $^{1} \cdot$ Phillis Mushati $^{1} \cdot$ Sibongile Mtetwa $^{1}$. \\ Dagmar Hanisch ${ }^{3}$. Sue Napierala ${ }^{4}$. Joanna Busza ${ }^{5}$. Sian Floyd ${ }^{6}$. Elizabeth Fearon ${ }^{7}$. Isolde Birdthistle ${ }^{5}$. \\ James R. Hargreaves ${ }^{7} \cdot$ Frances M. Cowan ${ }^{1,8}$
}

Published online: 20 February 2019

(c) The Author(s) 2019

\begin{abstract}
Young female sex-workers (FSW) aged 18-24 are at high risk of HIV due to high numbers of sexual partners, difficulty negotiating condom use, increased risk of gender-based violence, and limited access to services. Here we describe changes in sexual behaviours among young FSW across Zimbabwe between 2013 and 2016, and risk factors for prevalent HIV in 2013 and 2016. FSW $\geq 18$ years were recruited using respondent-driven sampling in 14 sites across Zimbabwe in 2013 and 2016 as part of the SAPPH-IRe trial. We collected data on socio-demographics and sexual behaviour and offered HIV testing. Statistical analyses were RDS-II weighted. Characteristics of young FSW aged 18-24 were described, stratified by age. Logistic regression was used to assess difference in sexual behaviours by reported HIV status between 2013 and 2016, and to explore associations with prevalent HIV in 2013 and 2016. 656 young FSW were recruited in 2013 and 503 in 2016. Characteristics of young FSW were similar across both surveys. HIV prevalence was similar at both time points (35\% vs $36 \%$ ) and rose steeply with age. Compared to young FSW in 2013, reported condom-less sex with a steady partner and condomless sex with clients was higher in 2016 among women self-reporting HIV negative status (OR $=6.41$; 95\% CI: 3.40-12.09; $\mathrm{P}<0.001)$ and $(\mathrm{OR}=1.69 ; 95 \% \mathrm{CI}: 1.14-2.51, \mathrm{P}=0.008)$, respectively, but not among young FSW self-reporting HIV positive status $(\mathrm{OR}=2.35 ; 95 \% \mathrm{CI}: 0.57-9.76 ; \mathrm{P}=0.236)$ and $(\mathrm{OR}=1.87 ; 95 \% \mathrm{CI}: 0.74-4.74 ; \mathrm{P}=0.186)$. After adjusting for age in 2016, young FSW who had ever been married had increased odds of testing HIV positive (OR=1.88; 95\% CI 1.04-3.39; $\mathrm{P}=0.036)$ compared with those who had never married. Young FSW who completed secondary education or higher were less likely to test HIV positive ( $\mathrm{OR}=0.41 ; 95 \% \mathrm{CI} 0.20-0.83 ; \mathrm{P}=0.012)$ compared with those with primary education or less. Young FSW remain at very high risk of HIV. Strategies to identify young FSW when they first start selling and refer them into services that address their economic, social and sexual vulnerabilities are critical.
\end{abstract}

Keywords HIV prevention · Young female sex-worker · Adolescent girls and young women · Young women who sell sex · Zimbabwe

Electronic supplementary material The online version of this article (https://doi.org/10.1007/s10461-019-02410-1) contains supplementary material, which is available to authorized users.

Sungai T. Chabata

sungai@ceshhar.co.zw; sungaichabata@gmail.com

1 Centre for Sexual Health, HIV/AIDS Research (CeSHHAR) Zimbabwe, 09 Monmouth Road, Avondale West, Harare, Zimbabwe

2 Department of Clinical Research, Faculty of Infectious and Tropical Diseases, London School of Hygiene and Tropical Medicine, London, UK

3 United Nations Population Fund, Harare, Zimbabwe

4 Women's Global Health Imperative, RTI International, San Francisco, CA, USA
5 Department of Population Health, Faculty of Epidemiology and Population Health, London School of Hygiene and Tropical Medicine, London, UK

6 Department of Infectious Disease Epidemiology, Faculty of Epidemiology and Population Health, London School of Hygiene and Tropical Medicine, London, UK

7 Department of Social and Environmental Health Research, Faculty of Public Health and Policy, London School of Hygiene and Tropical Medicine, London, UK

8 Department of International Public Health, Liverpool School of Tropical Medicine, Liverpool, UK 


\section{Introduction}

In sub-Saharan Africa, the burden of HIV is higher among women than men, and adolescent girls and young women (AGYW) bear the greatest burden of new infections [1]. In 2016, AGYW (aged 15-24 years) accounted for more than $60 \%$ of new infections among those aged 15-24 [1]. Young female sex-workers (FSW) are at particularly heightened HIV risk. In addition to the physiological, emotional and social vulnerabilities faced by AGYW as they transition into adulthood, young FSW face added challenges related to stigma, discrimination and criminalisation [2, 3], and reduced ability to negotiate condom use with sexual partners [4]. This results in a 'perfect storm' of synergistic vulnerabilities that increase their susceptibility to HIV, sexually transmitted infections (STIs) and unintended pregnancy, as well as violence, poor mental health and substance use. As a consequence, young FSW are a particularly important group for comprehensive prevention interventions $[5,6]$.

Despite their increased risk of HIV, STIs and unplanned pregnancies, young FSW are poorly engaged with sexual health and HIV prevention and care programmes, in part because of fear of stigma and discrimination from healthcare providers, older FSW, families and friends, and the possible legal repercussions of visiting healthcare services and disclosing their engagement in sex work [5, 7, 8].

Data on socio-economic characteristics and HIV risk behaviours among young FSW remain sparse in Africa, including in Zimbabwe, due to their lack of engagement in health services [7] and difficulty in reaching them for research. The SAPPH-IRe trial (Sisters Antiretroviral Programme for Prevention of HIV, an Integrated Response PACTR201312000722390) [9, 10] tested a community intervention to improve FSW engagement with prevention and care services in Zimbabwe. Using data from this trial we explored the characteristics and sexual behaviours of young FSW aged 18-24 at two time-points prior to the roll-out of the US Government's DREAMS (Determined, Resilient, Empowered, AIDS-free, Mentored and Safe) Partnership in Zimbabwe. Through the delivery of a combined package of HIV prevention interventions, DREAMS aims to reduce the risk of HIV among the most vulnerable AGYW, including young women who sell sex (YWSS), in ten sub-Saharan African countries [11]. We investigated trends in sexual risk behaviours over this time period to better interpret any future changes in behaviour following the introduction of DREAMS in Zimbabwe. We investigated whether these behaviours were associated with prevalent HIV in 2013 and 2016 [9]. Our hypothesis was that HIV prevalence would be higher among women reporting more years of sex work, and sexual risk behaviours would become less risky over time and differ by age. We aimed to identify characteristics and behaviours that put young FSW at high risk of HIV, which might be necessary for DREAMS and similar programmes to target among AGYW going forward.

\section{Methods}

\section{Study Setting}

The SAPPH-IRe trial was conducted in 14 communities in Zimbabwe where a national sex worker HIV prevention programme, 'Sisters with a Voice', had been running. The trial is described in detail elsewhere [10]. Briefly, the trial aimed to estimate the effect of a combination intervention on the proportion of all FSW who had a viral load $\geq 1000$ copies/mL (reflecting whether an individual is infectious) [9]. The trial was completed in 2016, before the introduction of the DREAMS Partnership, allowing us to describe the risk environment among young FSW prior to the roll-out of DREAMS. The trial sites were purposively selected to reflect a range of settings [9]. Women were eligible to participate in the trial baseline and endline surveys if they were aged 18 years or older, had exchanged sex for money or gifts in the preceding 30 days, and had lived at the site for at least the previous 6 months.

\section{Data Sources}

In this study, we used data from the SAPPH-IRe trial baseline and endline cross-sectional surveys. The baseline survey was conducted between 13th November and 20th December 2013 (2013 survey) and the endline survey between 11th April and 6th May 2016 (2016 survey). The surveys used respondent-driven sampling (RDS) to recruit two independent samples of FSW [9, 10, 12]. In these settings, sex is not commonly sold within brothels or other sex work specific venues, making RDS the most appropriate sampling method. As described elsewhere, prior to the RDS survey, geographic and social mapping was conducted over 2 to 3 days in each site [9]. This included informal discussions with trained peer educators, healthcare staff, and community informants. The mapping defined the geographic and social typology of sex work, determined if sex-workers at that site were well networked, and allowed for identification of FSW representative of these typologies (termed 'seeds') to initiate the RDS recruitment chains. In each location, between 6 and 8 seeds were invited to attend the survey site to complete a questionnaire and had a dried blood spot (DBS) taken for HIV antibody testing and, if positive, HIV viral load testing. All participants were also offered free HIV testing at the survey sites [10]. Seeds were then given two recruitment coupons 
to pass on to FSW peers. The women receiving a coupon ('recruits') who attended for interview were also given two coupons to give out to FSW in that location. We used an in-house coupon manager software to track coupons and all coupons were verified and redeemed only once. In all 14 sites, five iterations ('waves') of this process were performed for each survey. The sample size for each site was approximately 200 women, based on trial considerations [9]. The estimated population of FSW across these 14 sites ranged from 371 to 1409 therefore a sample of 200 women per site accounted for $14-54 \%$ of the target population across sites.

\section{Key Outcomes and Measures}

Data were restricted to women recruited who were aged 18-24. The primary outcome of interest was HIV prevalence among young FSW. Sexual risk behaviours explored included those related to sex work characteristics (e.g. duration of selling sex, number of clients per week), condom use at last sex, and condom-less sex with steady partners and/or clients. Condom-less sex was defined as not having used a condom with a sexual partner at least once in the last month. The questions used to assess condom-less sex were: "In the past month, how often did you use condoms with your steady partner?"; "In the past month, has there been an occasion when you did not use condoms with your steady partner?"; "In the past month, how often did you use condoms with your clients?" and "Think again about all your clients in the last month, have there been any times when you did not use condoms?" We measured common mental disorders using the validated Shona Symptom Questionnaire (SSQ-8) [13], which asks eight questions about mental health symptoms experienced in the previous 1 week. The SSQ-8 is a screening tool for common mental disorders, including depression and anxiety [13-15]. A score of six or more out of eight indicates risk of common mental disorders. Insufficient quantity of food was defined as reporting spending at least 1 day without eating in the past month because there was no food in the household.

\section{Laboratory Methods}

Blood samples were air-dried on filter papers and stored at room temperature until transported bi-weekly to the Flowcytometry Laboratory in Harare. If HIV antibodies were detected using AniLabsytems EIA kit (AniLabsystems Ltd, OyToilette 3, FIN-01720, Finland) then the sample was retested for HIV viral load using NucliSENS EasyQ HIV-1 v2.0, both to confirm HIV positive status and to quantify the viral load. For samples with a positive HIV antibody test using Anilab EIA, but an undetectable viral load, a second confirmatory ELISA was performed (Enzygnost Anti-HIV 1/2 Plus ELISA (Germany).

\section{Data Analyses}

We follow the STROBE-RDS guidelines in reporting our study by first describing the samples recruited at each survey site [16]. RDS makes a number of assumptions including that purposively selected seeds do not bias the final estimates and that the target population is networked. We generated recruitment trees to judge onward recruitment by FSW in both surveys. We assessed whether final estimates of key outcomes converged over the five waves of recruitment and whether the social networks of FSW appeared to have been disconnected (bottlenecks) using combined convergence and bottleneck plots in each site. We also assessed recruitment homophily with respect to age and prevalent HIV to understand if recruiters were more likely to recruit women of their own age and if women who tested HIV positive were more likely to recruit women who tested HIV positive, respectively.

All analyses were RDS-II weighted, with women's responses weighted by the inverse of the reported number of sex workers they knew i.e. the number of other women that she could have recruited to the survey [17]. The rationale for RDS-II weighting has been described in detail elsewhere $[12,18]$. We pooled data from across the fourteen sites and both time points and normalised the RDS-II weights by site, dropping seeds and including a fixed term for site in all regression analysis. In order to minimise the risk of duplicate enrolment in each survey, we constructed a check identifier for each participant consisting of the first letter of her first name, the last three letters of her surname and her date of birth. Comparing check identifiers and questionnaire responses between 2013 and 2016 surveys suggested that fifteen young FSW (2\% of those enrolled in 2013; $3 \%$ of those enrolled in 2016) were likely to have participated in both surveys. HIV prevalence and sexual behaviour estimates did not change after excluding the fifteen individuals, therefore, in both years, all participants were retained in the analysis. Socio-demographic characteristics and sexual risk behaviours were analysed descriptively among young FSW aged 18-19 and aged 20-24. Where there were a small number of women within categories of a categorical variable, for example duration in sex work, variables were collapsed into fewer categories to overcome issues of sparse data.

Weighted logistic regression models, with sexual risk behaviour as outcome and survey year as exposure were used to assess evidence for changes in sexual risk behaviours between the 2013 and 2016 surveys, separately for young FSW who self-reported HIV negative status and those who self-reported HIV positive status. This was done separately by self-reported HIV status, to understand if adoption of 
safer sexual behaviours differed between women who reported knowing their HIV negative or positive status.

We intentified the socio-economic factors and sexual risk behaviours associated with prevalent HIV (rapid HIV test results) at each survey, by first using univariable logistic regression. Factors associated with prevalent HIV at $\mathrm{P} \leq 0.10$ in univariable analysis were included into multivariable regression models, firstly adjusted for age at survey, and secondly adjusted for all factors that were associated with prevalent HIV in the univariable analysis with some conceptual framework for how these variables might be related, to understand factors independently associated with prevalent HIV. Age at time of the survey was included categorically. 2013 data will be presented in the Online Appendix and 2016 data in the main paper.

\section{Results}

A total of 2722 FSW were recruited in 2013, of whom $24 \%(n=656)$ were young FSW. In 2016, 2883 FSW were recruited, of whom 17\% $(n=503)$ were young FSW. Extensive RDS diagnostics have been reported elsewhere [10, 19] and the findings apply to these data. Here we report RDS diagnostics of prevalent HIV and sexual risk behaviours.

In the 2013 survey, 90 FSW were seeds, 2804 FSW were examined for eligibility, and 2722 (97\%) were eligible for the study. Overall, 3449 coupons were distributed of which 2714 (79\%) were returned. In the 2016 survey, 92 FSW were seeds, 3025 FSW were examined for eligibility, and 2883 (95\%) were eligible for the study. Overall, 3977 coupons were distributed of which 2933 (74\%) were returned.

In the 2013 (Online Appendix 1) and 2016 surveys (Fig. 1), seeds were productive in recruiting FSW. In the 2013 survey, the number of recruits by seed ranged from 5 to 59 and in 2016 survey from 8 to 59 across sites. We judged that convergence appeared to have been achieved by the final sample size for HIV prevalence and that social networks of FSW in the respective sites were well connected (Fig. 2). This was true for sexual risk behaviours in 2013 and 2016 surveys (Online Appendix 1). Recruitment homophily on age and HIV prevalence was low in 2013 and 2016 surveys (Online Appendix 1).

The socio-demographic and behavioural characteristics of young FSW were similar across both surveys (Table 1). Two thirds of young FSW had some secondary education or higher. In 2013, 63\% of young FSW aged 18-19 had never married versus $49 \%$ in 2016 . Among young FSW aged 20-24, a similar proportion had never married in 2013 and 2016 (32\% vs 31\%). Overall, around a quarter of young FSW reported initiating sex work before the age of 18 in both surveys. In 2013, 27\% of young FSW aged 18-19 reported $\geq 10$ clients in the last week compared to $35 \%$ in 2016. Among young FSW aged 20-24, a similar proportion reported $\geq 10$ clients in the last week in 2013 and 2016 (27\% vs 30\%). A higher proportion of young FSW aged 18-19 were aware of their of HIV positive status in 2016 compared to 2013 (54\% vs 45\%) and this was true for young FSW aged 20-24.

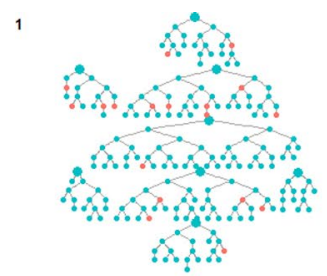

6

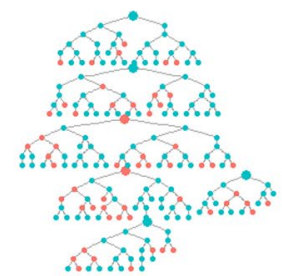

11

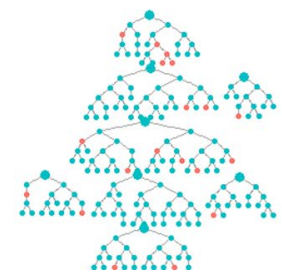

2

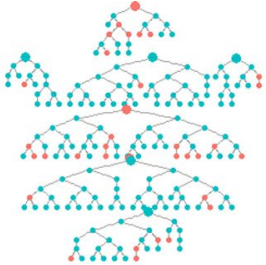

7

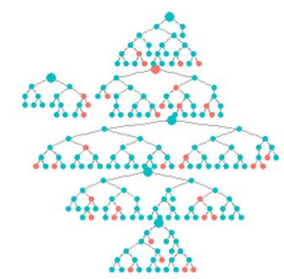

12

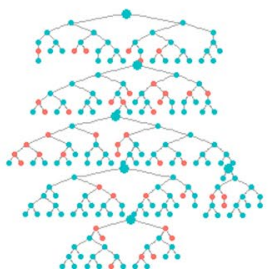

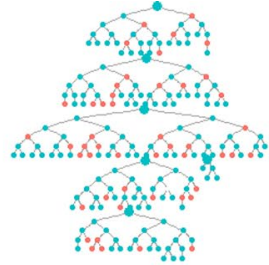

8
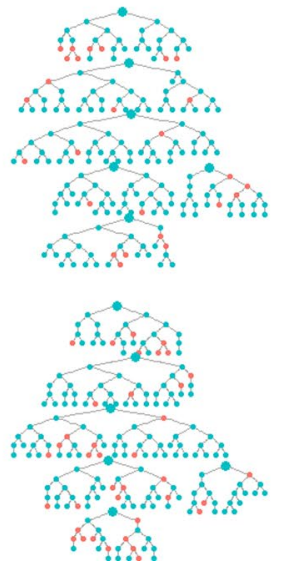

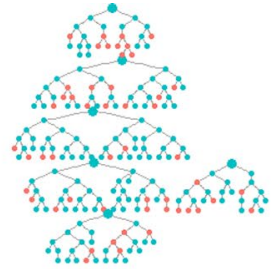

9
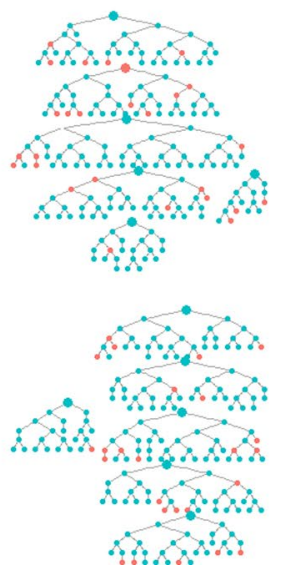

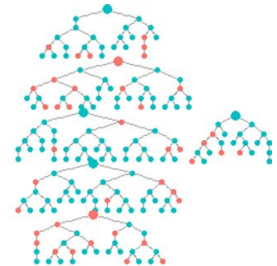

10

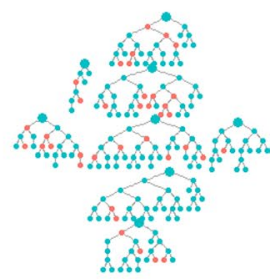

Fig. 1 Recruitment tree diagrams. Participants are depicted by circles with their recruits shown as the connected circles below them. The larger circles denote seeds. Red circles represent women aged 18-24 and blue circles represent women aged $\geq 25$ (Colour figure online) 


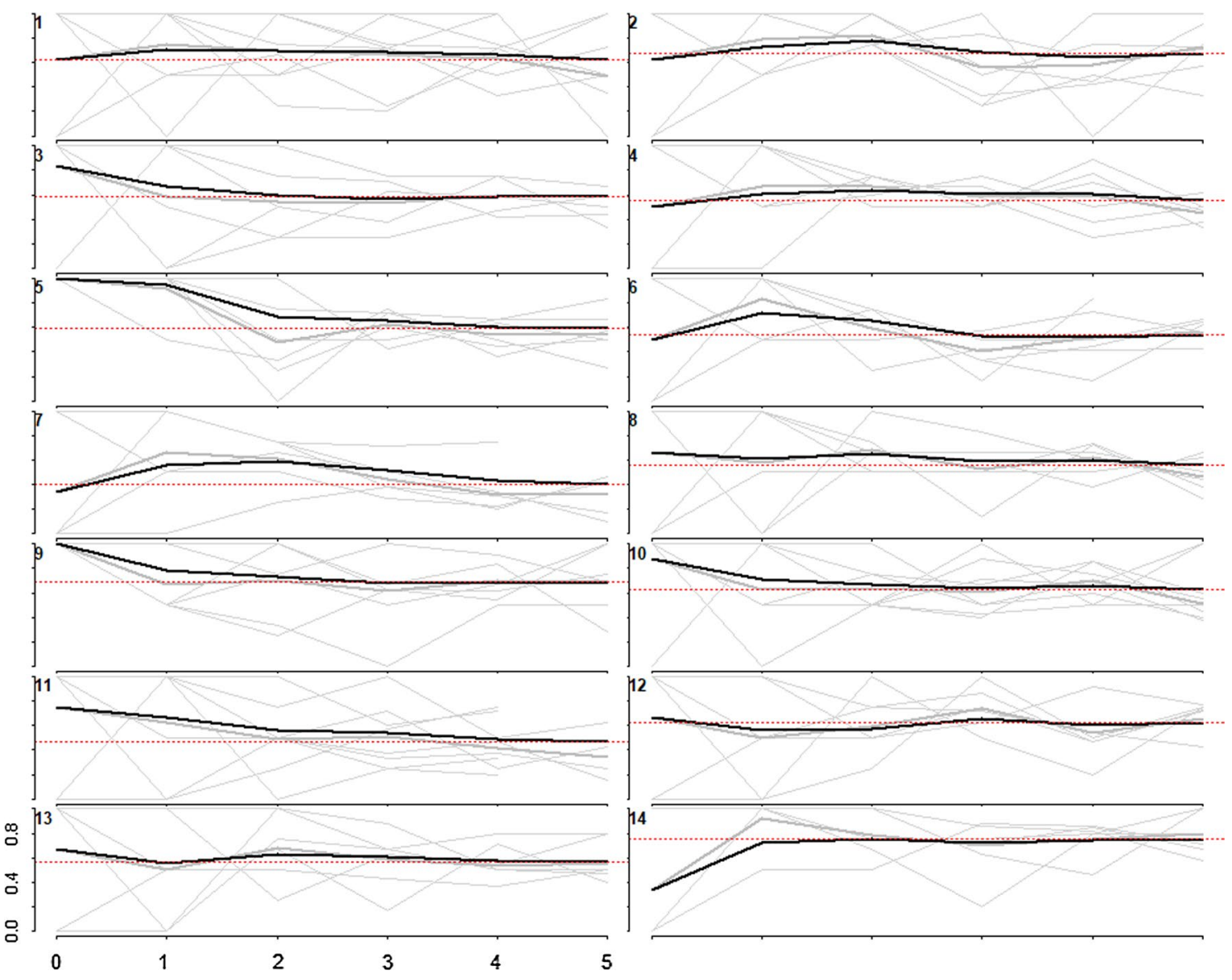

Fig. 2 Convergence of the proportion of HIV positive FSW. The heavy black lines indicate the cumulative RDS-II weighted estimate overall for each site, while the grey lines are unweighted proportions for each seed, by sample wave (Colour figure online)

Between 2013 and 2016, reported sexual behaviours changed most among women who self-reported their HIV negative status. In 2016, there was evidence that a higher proportion of young FSW who self-reported their HIV negative status were in sex work for $\geq 3$ years relative to 2013 (48\% vs 35\%, respectively; OR $=1.68$; 95\% CI 1.13-2.49; $\mathrm{P}=0.010$ ) (Table 2). In 2016, young FSW reporting HIV negative status were more likely to report having a steady partner compared to 2013 (OR=1.63; 95\% CI 1.07-2.47; $\mathrm{P}=0.022$ ). Compared to young FSW participating in the 2013 survey, condom-less sex with a steady partner in the past month was higher in 2016 among women selfreporting HIV negative status (31\% vs 70\%, respectively; $\mathrm{OR}=6.41 ; 95 \%$ CI $3.40-12.09 ; \mathrm{P}<0.001)$ but not among women self-reporting HIV positive status ( $\mathrm{OR}=2.35 ; 95 \%$ CI $0.57-9.76 ; \mathrm{P}=0.236$ ), and condom-less sex with clients in the past month evidently increased among women who reported being HIV negative $(\mathrm{OR}=1.69$; 95\% CI 1.14-2.51, $\mathrm{P}=0.008$ ) but there was no evidence of an increase among those who reported knowing their HIV positive status $(\mathrm{OR}=1.87 ; 95 \%$ CI $0.74-4.74 ; \mathrm{P}=0.186)$. Figure 3 shows the overall changes in condom variables and HIV prevalence between 2013 and 2016, with site specific values denoted by dots to show the variability of proportions and prevalence across sites. There was evidence that ever being forced to have sex was higher in 2016 relative to 2013 among women who reported being HIV negative $(11.1 \%$ vs $4.5 \%$, respectively; $\mathrm{OR}=2.63 ; 95 \%$ CI $1.03-6.75 ; \mathrm{P}=0.044$ ).

In univariable analysis of factors associated with prevalent HIV in 2013 (Online Appendix 2), there was evidence that age and marital status were associated with prevalent HIV. However, there was no evidence of an association after adjusting for age at time of the survey, marital status and number of FSW who are close friends. In 2016, there was evidence that age, marital status, educational attainment and reported number of clients in the previous week were crudely associated with prevalent HIV (Table 3), with no evidence that HIV prevalence was higher among women selling sex for $\geq 5$ years relative to women selling sex for $0-2$ years $(28.4 \%$ vs $38.1 \%$; OR $=0.66$; $95 \%$ CI $0.32-1.35$; $\mathrm{P}=0.302$ ) and little evidence of an association with condom use variables, experience of violence or alcohol use.

After adjusting for age, there was strong evidence that marital status, educational attainment and reported number 
Table 1 Socio-demographic and sexual behavioural characteristics of young FSW by age, 2013 (N=656) and 2016 (N=503) (RDS-II weighted)

\begin{tabular}{|c|c|c|c|c|c|c|c|c|}
\hline & \multicolumn{4}{|c|}{$2013(\mathrm{~N}=656)$} & \multicolumn{4}{|c|}{$2016(\mathrm{~N}=503)$} \\
\hline & \multirow{2}{*}{\multicolumn{2}{|c|}{$\begin{array}{l}18-19 \text { years } \\
\mathrm{N}=109\end{array}$}} & \multirow{2}{*}{\multicolumn{2}{|c|}{$\begin{array}{l}20-24 \text { years } \\
\mathrm{N}=547\end{array}$}} & \multirow{2}{*}{\multicolumn{2}{|c|}{$\begin{array}{l}18-19 \text { years } \\
\mathrm{N}=51\end{array}$}} & \multirow{2}{*}{\multicolumn{2}{|c|}{$\begin{array}{l}20-24 \text { years } \\
\mathrm{N}=452\end{array}$}} \\
\hline & & & & & & & & \\
\hline & $\mathrm{n}$ & $(\%)$ & $\mathrm{n}$ & $(\%)$ & $\mathrm{N}$ & $(\%)$ & $\mathrm{n}$ & $(\%)$ \\
\hline \multicolumn{9}{|l|}{ Marital status } \\
\hline Married/ living together as if married & 0 & 0.0 & 3 & 0.5 & 1 & 0.8 & 3 & 1.6 \\
\hline Divorced/ separated & 45 & 37.5 & 343 & 64.9 & 19 & 49.5 & 294 & 66.4 \\
\hline Widowed & 0 & 0.0 & 19 & 2.8 & 1 & 0.8 & 8 & 1.0 \\
\hline Never been married & 64 & 62.6 & 182 & 31.7 & 30 & 49.0 & 147 & 31.0 \\
\hline \multicolumn{9}{|l|}{ Highest level of education } \\
\hline None & 1 & 1.4 & 8 & 1.9 & 0 & 0.0 & 6 & 2.1 \\
\hline Primary level & 38 & 34.8 & 106 & 21.3 & 13 & 30.4 & 87 & 22.1 \\
\hline Some secondary & 52 & 49.0 & 229 & 44.3 & 28 & 55.8 & 178 & 39.2 \\
\hline Complete secondary or higher & 17 & 14.8 & 203 & 32.5 & 10 & 13.9 & 181 & 36.6 \\
\hline \multicolumn{9}{|l|}{ Tribe } \\
\hline Shona & 85 & 68.3 & 427 & 74.0 & 41 & 81.3 & 334 & 71.9 \\
\hline Ndebele & 18 & 24.3 & 47 & 11.4 & 7 & 10.5 & 48 & 11.2 \\
\hline Kalanga & 0 & 0.0 & 11 & 1.4 & 0 & 0.0 & 1 & 0.1 \\
\hline Other & 6 & 7.4 & 62 & 13.3 & 3 & 8.1 & 68 & 16.8 \\
\hline \multicolumn{9}{|l|}{ Religion } \\
\hline Christian & 56 & 57.2 & 267 & 49.0 & 32 & 62.1 & 263 & 53.2 \\
\hline Muslim & 0 & 0.0 & 2 & 0.4 & 1 & 0.8 & 3 & 1.1 \\
\hline African traditional & 0 & 0.0 & 1 & 0.2 & 0 & 0.0 & 1 & 0.2 \\
\hline Other & 11 & 14.6 & 35 & 6.2 & 8 & 10.5 & 54 & 13.8 \\
\hline No religion & 42 & 28.1 & 241 & 44.1 & 10 & 26.6 & 131 & 31.7 \\
\hline \multicolumn{9}{|l|}{ Number of children } \\
\hline 0 & 46 & 46.4 & 152 & 30.6 & 23 & 43.2 & 119 & 30.3 \\
\hline $1-2$ & 52 & 47.4 & 329 & 59.3 & 26 & 54.4 & 268 & 54.9 \\
\hline $3+$ & 11 & 6.2 & 66 & 10.2 & 2 & 2.4 & 65 & 14.8 \\
\hline \multicolumn{9}{|l|}{ No food for one day in the past month } \\
\hline No & 70 & 63.0 & 325 & 60.0 & 36 & 67.4 & 308 & 67.7 \\
\hline Yes & 39 & 37.0 & 222 & 40.0 & 15 & 32.6 & 143 & 32.3 \\
\hline \multicolumn{9}{|l|}{ Age at start of sex work } \\
\hline$\leq 15$ & 19 & 16.2 & 26 & 5.6 & 9 & 18.6 & 21 & 5.9 \\
\hline $16-17$ & 56 & 51.8 & 63 & 9.6 & 32 & 69.7 & 68 & 12.6 \\
\hline $18-24$ & 34 & 32.0 & 458 & 84.7 & 10 & 11.7 & 362 & 81.5 \\
\hline \multicolumn{9}{|l|}{ Duration in sex work (years) } \\
\hline $0-2$ & 82 & 79.7 & 300 & 60.5 & 36 & 71.4 & 204 & 46.7 \\
\hline $3-4$ & 22 & 15.6 & 165 & 26.0 & 14 & 28.2 & 161 & 34.5 \\
\hline$\geq 5$ & 5 & 4.7 & 82 & 13.5 & 1 & 0.4 & 86 & 18.8 \\
\hline \multicolumn{9}{|l|}{ Number of clients in the last week } \\
\hline $0-4$ & 47 & 55.8 & 225 & 46.4 & 21 & 42.7 & 181 & 41.4 \\
\hline $5-9$ & 24 & 17.7 & 141 & 26.8 & 16 & 22.6 & 136 & 29.2 \\
\hline$\geq 10$ & 38 & 26.5 & 181 & 26.9 & 14 & 34.7 & 134 & 29.5 \\
\hline \multicolumn{9}{|c|}{ Relationship with other female sex-workers in one's location } \\
\hline Good & 63 & 56.8 & 323 & 62.1 & 36 & 59.4 & 295 & 63.1 \\
\hline Neither good nor bad & 31 & 28.6 & 174 & 28.7 & 12 & 31.8 & 132 & 33.0 \\
\hline $\mathrm{Bad}$ & 8 & 6.5 & 32 & 5.8 & 1 & 0.3 & 15 & 2.2 \\
\hline No relationship & 7 & 8.1 & 18 & 3.3 & 2 & 8.5 & 9 & 1.7 \\
\hline
\end{tabular}


Table 1 (continued)

\begin{tabular}{ll}
$\frac{2013(\mathrm{~N}=656)}{18-19 \text { years }}$ & $\frac{20-24 \text { years }}{\mathrm{N}=109}$ \\
\hline $\mathrm{n} \quad(\%)$ & $\frac{\mathrm{N}=547}{\mathrm{n} \quad(\%)}$
\end{tabular}

$\begin{array}{ll}\frac{2016(\mathrm{~N}=503)}{18-19 \text { years }} & \frac{20-24 \text { years }}{\mathrm{N}=51} \\ \frac{\mathrm{N}=452}{\mathrm{~N} \quad(\%)} & \frac{\mathrm{n} \quad(\%)}{}\end{array}$

No. of female sex-workers who are close friends

$\leq 1$

2-3

$\geq 4$

Alcohol consumption in the past 12 months

Never

Once a month or less

2-4 times per month

2-3 times per week

4 or more times per week

Symptoms of common mental disorder

No

Yes

Experience of physical violence from steady partner

No

Yes

Experience of physical violence from client

No

Yes

Ever forced to have sexual intercourse

No

Yes

Self-reported HIV status

Negative

Positive

Rapid HIV test result

Negative

Positive

Knowledge of HIV positive status ${ }^{\mathrm{a}}$

No

Yes

\begin{tabular}{|c|c|c|c|c|c|c|}
\hline 20.6 & 156 & 26.6 & 19 & 34.2 & 169 & 35.2 \\
\hline 61.6 & 291 & 55.9 & 24 & 57.2 & 188 & 44.6 \\
\hline 17.8 & 100 & 17.5 & 8 & 8.6 & 94 & 20.2 \\
\hline 47.4 & 184 & 36.1 & 19 & 30.7 & 131 & 31.4 \\
\hline 5.9 & 59 & 12.5 & 3 & 7.4 & 35 & 6.4 \\
\hline 9.2 & 77 & 13.7 & 4 & 2.3 & 51 & 11.8 \\
\hline 20.4 & 79 & 13.1 & 13 & 27.1 & 116 & 27.2 \\
\hline 16.9 & 148 & 24.6 & 12 & 32.4 & 118 & 23.2 \\
\hline 53.3 & 268 & 51.4 & 41 & 84.8 & 311 & 68.2 \\
\hline 46.7 & 276 & 48.6 & 10 & 15.2 & 138 & 31.8 \\
\hline 62.7 & 305 & 59.5 & 27 & 50.4 & 242 & 58.3 \\
\hline 37.3 & 242 & 40.5 & 24 & 49.6 & 209 & 41.7 \\
\hline 77.1 & 397 & 76.2 & 29 & 52.6 & 327 & 75.9 \\
\hline 22.9 & 150 & 23.8 & 22 & 47.4 & 124 & 24.1 \\
\hline 90.4 & 528 & 96.4 & 46 & 90.7 & 412 & 89.9 \\
\hline 9.6 & 19 & 3.6 & 5 & 9.3 & 39 & 10.1 \\
\hline 85.0 & 403 & 82.8 & 43 & 86.8 & 354 & 74.7 \\
\hline 15.0 & 100 & 17.2 & 5 & 13.2 & 88 & 25.3 \\
\hline 73.3 & 339 & 63.0 & 39 & 79.3 & 290 & 62.0 \\
\hline 26.7 & 208 & 37.0 & 12 & 20.7 & 161 & 38.0 \\
\hline 55.4 & 116 & 61.0 & 9 & 45.7 & 77 & 38.1 \\
\hline 44.6 & 92 & 39.0 & 3 & 54.3 & 84 & 61.9 \\
\hline
\end{tabular}

${ }^{\text {a }}$ Proportion reported HIV positive among those who tested HIV positive during the survey

of clients in the previous week were associated with prevalent HIV. Young FSW who had ever been married had a higher prevalence of HIV (adjOR $=1.88$; 95\% CI 1.04-3.39; $\mathrm{P}=0.036$ ) compared with those never married. Young FSW with complete secondary education or higher were less likely to test HIV positive compared to women with primary education or less $(\operatorname{adjOR}=0.41 ; 95 \%$ CI $0.20-0.83$; $\mathrm{P}=0.012)$. Young FSW reporting $\geq 10$ clients in the last week $(\operatorname{adjOR}=1.88 ; 95 \%$ CI $1.01-3.51 ; \mathrm{P}=0.043)$ were more likely to be HIV positive compared to those reporting $0-4$ clients in the last week.

Among women aged 20-24, HIV prevalence was $38.0 \%$ compared to $20.7 \%$ among women aged 18-19 and after adjusting for marital status, educational attainment and reported number of clients in the previous week, there was evidence that HIV prevalence differed by age $(\operatorname{adjOR}=3.09$; 95\% CI 1.09-8.81; $\mathrm{P}=0.035)$.

\section{Discussion}

We used data from a completed trial to explore the characteristics and sexual behaviours of young FSW aged 18 to 24 at two time-points separated by 30 months, and investigated whether these factors were associated with prevalent HIV in 2013 and 2016. In both surveys, over one-third of the 


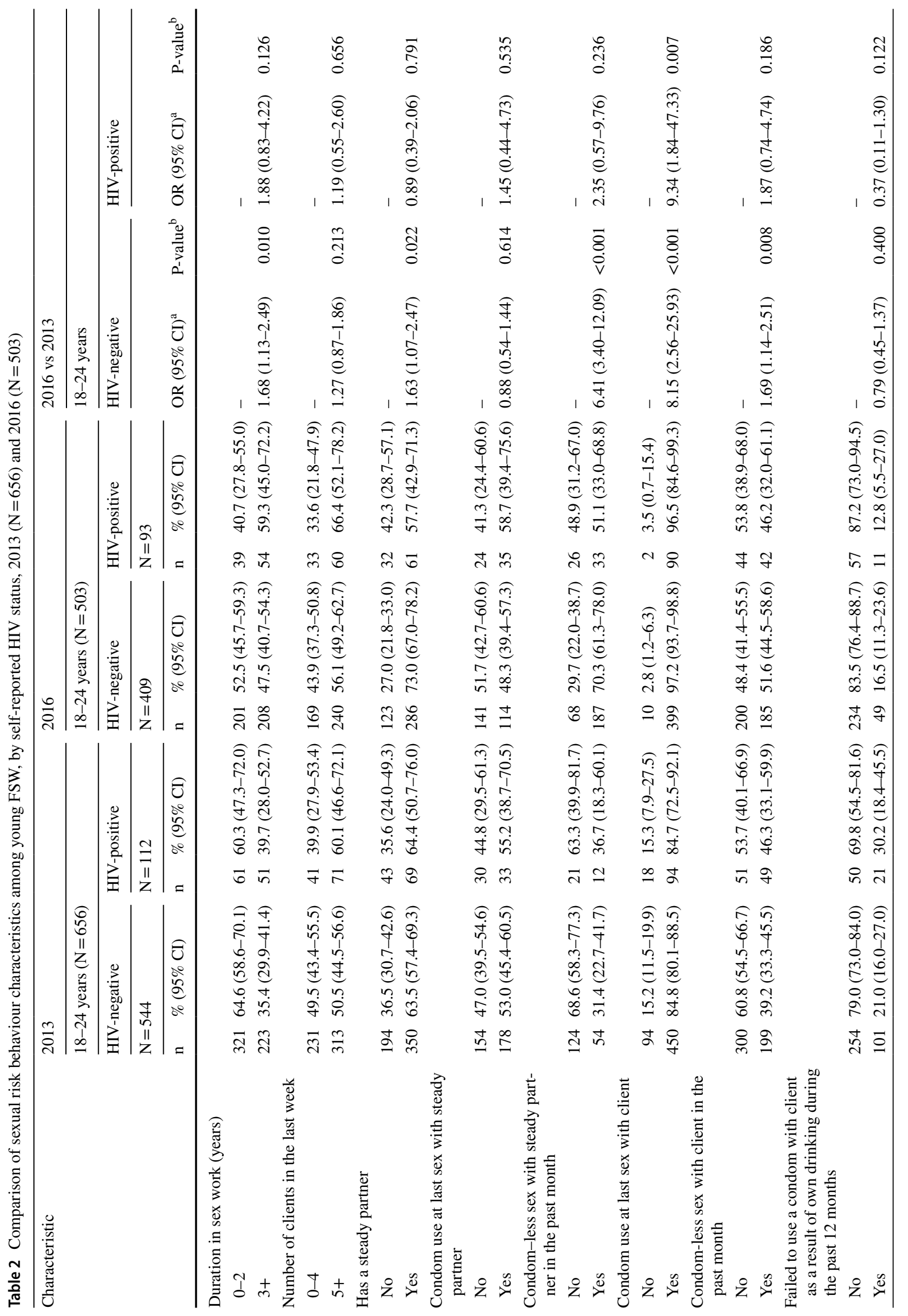




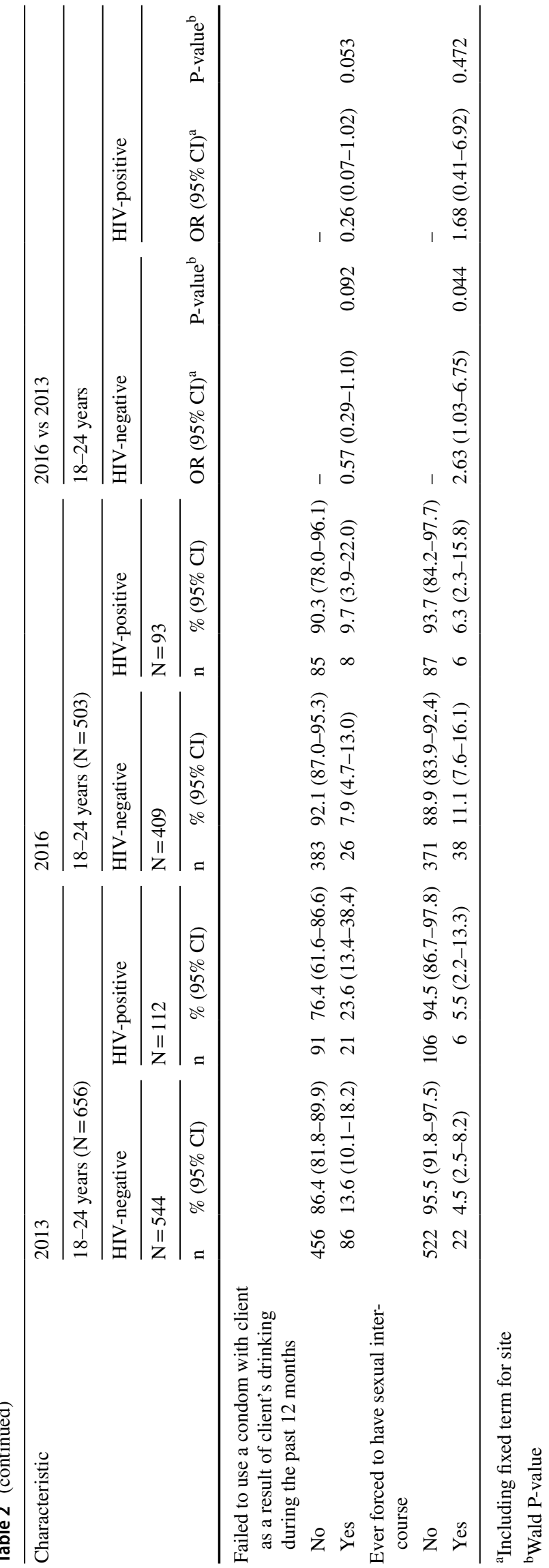

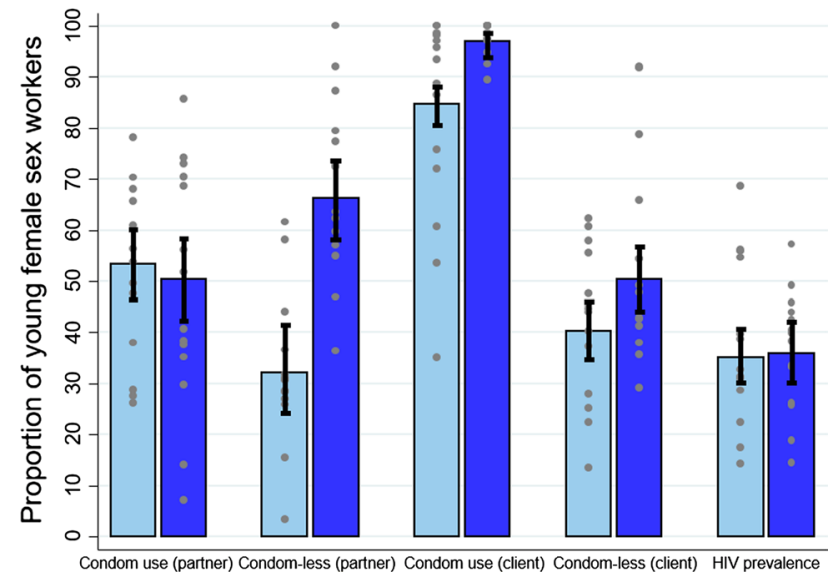

Fig. 3 Condom use at last sex and condom-less sex with steady partner, condom use at last sex and condom-less sex with client, and HIV prevalence overall among young female sex-workers (aged 18-24) and by site (grey spots = sites; light blue bars $=2013$ survey; dark blue bars $=2016$ survey) (Colour figure online)

women tested HIV positive, confirming that young FSW in Zimbabwe are at consistently high risk of infection. A lower proportion were aware of their HIV positive status in 2013. As seen among other young women in southern Africa, HIV prevalence was higher amongst those young FSW who were divorced or separated [20]. Young FSW reported high numbers of clients in the previous week and high rates of condom-less sex in the past month with a steady partner or client. In 2016, we found that women who were ever married, had less education, and who reported a higher number of clients in the past week were more likely to test HIVpositive but found no evidence that duration of selling sex or reported condom use were associated with HIV.

In 2016, HIV prevalence among young FSW aged 20-24 was approximately four-times higher than the HIV prevalence of $10 \%$ among women aged 20-24 in the general population [21]. It was also 1.5 times higher than in young FSW aged 18-19, suggestive of high HIV incidence. This hypothesis is supported by a cohort analysis of the Sisters with a Voice programmatic data, which estimated an HIV incidence of $11 \%$ per year among women aged $<26$ between 2009 and 2013 [22].

We hypothesised that HIV prevalence would be higher among women reporting more years of sex work but found no association; in 2016 HIV prevalence seemed to be decreasing with increased duration in sex work. Prevalent HIV was higher among women reporting more clients in the past week, highlighting the risk associated with "high activity" sex work. We also found an association with reporting ever being married, possibly because it is difficult for married women to use condoms with their husbands. Alternatively it is possible that women widowed by an HIV-positive husband or separated from their partner because of their 
Table 3 Factors associated with prevalent HIV among young FSW aged 18-24 in Zimbabwe, 2016 (N=503)

\begin{tabular}{|c|c|c|c|c|c|c|c|c|}
\hline Characteristic & $\mathrm{N}(\%)$ & $\begin{array}{l}\text { Number of young } \\
\text { female sex-workers } \\
\text { tested HIV-positive } \\
\text { during the survey } \\
(\mathrm{n}=173) \mathrm{n}(\%)\end{array}$ & $\begin{array}{l}\text { Crude OR } \\
(95 \% \mathrm{CI})\end{array}$ & $\mathrm{P}$-value & $\begin{array}{l}\text { Age adjusted OR } \\
(95 \% \mathrm{CI})\end{array}$ & P-value & $\begin{array}{l}\text { Adjusted }^{\mathrm{a}} \text { OR } \\
(95 \% \mathrm{CI})\end{array}$ & P-value \\
\hline $\begin{array}{l}\text { Age at time of } \\
\text { survey }\end{array}$ & & & & 0.029 & & & & 0.035 \\
\hline $18-19$ & $51(12.5)$ & $12(20.7)$ & 1 & & & & 1 & \\
\hline $20-24$ & $451(87.5)$ & $161(38.0)$ & $3.06(1.12-8.38)$ & & & & $3.09(1.09-8.81)$ & \\
\hline Marital status & & & & 0.013 & & 0.036 & & 0.060 \\
\hline Never married & $176(33.0)$ & $41(23.7)$ & 1 & & 1 & & 1 & \\
\hline Ever married & $326(67.0)$ & $132(41.9)$ & $2.10(1.17-3.77)$ & & $1.88(1.04-3.39)$ & & $1.77(0.98-3.21)$ & \\
\hline $\begin{array}{l}\text { Highest level of } \\
\text { education }\end{array}$ & & & & 0.025 & & 0.012 & & 0.031 \\
\hline $\begin{array}{l}\text { Primary school } \\
\text { or less }\end{array}$ & $105(24.7)$ & $47(47.4)$ & 1 & & 1 & & 1 & \\
\hline $\begin{array}{l}\text { Some secondary } \\
\text { school }\end{array}$ & $206(41.4)$ & $76(36.3)$ & $0.66(0.33-1.30)$ & & $0.68(0.34-1.34)$ & & $0.69(0.35-1.36)$ & \\
\hline $\begin{array}{l}\text { Complete second- } \\
\text { ary or higher }\end{array}$ & $191(33.9)$ & $50(26.9)$ & $0.45(0.22-0.90)$ & & $0.41(0.20-0.83)$ & & $0.46(0.22-0.94)$ & \\
\hline Number of children & & & & 0.462 & & & & \\
\hline 0 & $141(31.7)$ & $54(41.9)$ & 1 & & & & & \\
\hline $1-2$ & $294(55.0)$ & $96(32.1)$ & $0.61(0.34-1.10)$ & & & & & \\
\hline$\geq 3$ & $67(13.3)$ & $23(37.3)$ & $0.89(0.37-2.14)$ & & & & & \\
\hline $\begin{array}{l}\text { Duration in sex } \\
\text { work }\end{array}$ & & & & 0.302 & & & & \\
\hline $0-2$ & $240(49.8)$ & $83(38.1)$ & 1 & & & & & \\
\hline $3-4$ & $175(33.7)$ & $56(36.2)$ & $0.92(0.51-1.67)$ & & & & & \\
\hline$\geq 5$ & $87(16.5)$ & $34(28.4)$ & $0.66(0.32-1.35)$ & & & & & \\
\hline $\begin{array}{l}\text { Number of clients } \\
\text { in the last week }\end{array}$ & & & & 0.068 & & 0.043 & & 0.090 \\
\hline $0-4$ & $202(41.5)$ & $56(28.9)$ & 1 & & 1 & & 1 & \\
\hline $5-9$ & $152(28.3)$ & $55(37.7)$ & $1.60(0.84-3.05)$ & & $1.58(0.82-3.04)$ & & $1.45(0.74-2.85)$ & \\
\hline$\geq 10$ & $148(30.2)$ & $62(43.8)$ & $1.79(0.94-3.44)$ & & $1.88(1.01-3.51)$ & & $1.70(0.90-3.22)$ & \\
\hline $\begin{array}{l}\text { Condom use at last } \\
\text { sex with steady } \\
\text { partner }\end{array}$ & & & & 0.635 & & & & \\
\hline No & 165 (49.5) & $54(29.1)$ & 1 & & & & & \\
\hline Yes & $149(50.5)$ & $48(32.5)$ & $1.18(0.59-2.38)$ & & & & & \\
\hline $\begin{array}{l}\text { Condom-less sex } \\
\text { with steady part- } \\
\text { ner in the past } \\
\text { month }\end{array}$ & & & & 0.165 & & & & \\
\hline No & 94 (33.7) & $33(37.3)$ & 1 & & & & & \\
\hline Yes & $220(66.3)$ & 69 (27.6) & $0.58(0.27-1.25)$ & & & & & \\
\hline $\begin{array}{l}\text { Condom use at last } \\
\text { sex with client }\end{array}$ & & & & 0.96 & & & & \\
\hline No & $12(3.0)$ & $3(33.6)$ & 1 & & & & & \\
\hline Yes & 489 (97.0) & 169 (35.6) & $1.05(0.15-6.03)$ & & & & & \\
\hline $\begin{array}{l}\text { Condom-less sex } \\
\text { with client in the } \\
\text { past month }\end{array}$ & & & & 0.277 & & & & \\
\hline No & 244 (49.6) & 77 (36.6) & 1 & & & & & \\
\hline Yes & $227(50.4)$ & $80(32.5)$ & $0.73(0.41-1.29)$ & & & & & \\
\hline
\end{tabular}


Table 3 (continued)

\begin{tabular}{|c|c|c|c|c|c|c|c|c|}
\hline Characteristic & $\mathrm{N}(\%)$ & $\begin{array}{l}\text { Number of young } \\
\text { female sex-workers } \\
\text { tested HIV-positive } \\
\text { during the survey } \\
(\mathrm{n}=173) \mathrm{n}(\%)\end{array}$ & $\begin{array}{l}\text { Crude OR } \\
(95 \% \mathrm{CI})\end{array}$ & P-value & $\begin{array}{l}\text { Age adjusted OR } \\
(95 \% \mathrm{CI})\end{array}$ & P-value & $\begin{array}{l}\text { Adjusted }^{\mathrm{a}} \text { OR } \\
(95 \% \mathrm{CI})\end{array}$ & P-value \\
\hline $\begin{array}{l}\text { Experience of } \\
\text { physical violence } \\
\text { from steady } \\
\text { partner }\end{array}$ & & & & 0.917 & & & & \\
\hline No & $269(57.3)$ & $87(36.2)$ & 1 & & & & & \\
\hline Yes & $233(42.7)$ & $86(35.4)$ & $0.97(0.58-1.63)$ & & & & & \\
\hline $\begin{array}{l}\text { Experience of } \\
\text { physical violence } \\
\text { from client }\end{array}$ & & & & 0.944 & & & & \\
\hline No & $356(73.0)$ & 114 (35.7) & 1 & & & & & \\
\hline Yes & $146(27.0)$ & $59(36.4)$ & $1.08(0.54-1.77)$ & & & & & \\
\hline $\begin{array}{l}\text { Ever forced to have } \\
\text { sexual inter- } \\
\text { course }\end{array}$ & & & & 0.523 & & & & \\
\hline No & $458(90.0)$ & $154(35.5)$ & 1 & & & & & \\
\hline Yes & $44(10.0)$ & $19(39.4)$ & $1.32(0.57-3.06)$ & & & & & \\
\hline $\begin{array}{l}\text { Alcohol use in the } \\
\text { past } 12 \text { months }\end{array}$ & & & & 0.699 & & & & \\
\hline Never & $150(31.3)$ & $46(36.0)$ & 1 & & & & & \\
\hline $\begin{array}{l}\text { Once a month or } \\
\text { less }\end{array}$ & $38(6.5)$ & $12(45.0)$ & $1.61(0.50-5.17)$ & & & & & \\
\hline $\begin{array}{l}2-4 \text { times per } \\
\text { month }\end{array}$ & 55 (10.6) & $16(20.2)$ & $0.50(0.20-1.24)$ & & & & & \\
\hline $\begin{array}{l}\text { 2-3 times per } \\
\text { week }\end{array}$ & $129(27.2)$ & $47(35.4)$ & $1.09(0.54-2.22)$ & & & & & \\
\hline $\begin{array}{l}4 \text { or more times } \\
\text { per week }\end{array}$ & $130(24.4)$ & $52(40.4)$ & $1.20(0.58-2.48)$ & & & & & \\
\hline $\begin{array}{l}\text { No food for one } \\
\text { day in the past } \\
\text { month }\end{array}$ & & & & 0.376 & & & & \\
\hline No & 344 (67.6) & $120(37.4)$ & 1 & & & & & \\
\hline Yes & $158(32.4)$ & $53(32.7)$ & $0.78(0.45-1.35)$ & & & & & \\
\hline $\begin{array}{l}\text { Relationship with } \\
\text { other FSW in } \\
\text { one's location }\end{array}$ & & & & 0.499 & & & & \\
\hline Good & 331 (62.7) & $110(35.2)$ & 1 & & & & & \\
\hline $\begin{array}{l}\text { Neither good nor } \\
\text { bad }\end{array}$ & $144(32.8)$ & $53(35.5)$ & $1.12(0.62-2.02)$ & & & & & \\
\hline $\begin{array}{l}\text { Bad or no rela- } \\
\text { tionship }\end{array}$ & $27(4.5)$ & $10(47.2)$ & $1.94(0.64-5.91)$ & & & & & \\
\hline $\begin{array}{l}\text { No. of FSW who } \\
\text { are close friends }\end{array}$ & & & & 0.201 & & & & \\
\hline$\leq 1$ & $188(35.1)$ & $70(36.8)$ & 1 & & & & & \\
\hline $2-3$ & $212(46.1)$ & $77(40.8)$ & $1.26(0.68-2.31)$ & & & & & \\
\hline$\geq 4$ & $102(18.8)$ & $26(22.0)$ & $0.47(0.21-1.05)$ & & & & & \\
\hline $\begin{array}{l}\text { Symptoms of } \\
\text { common mental } \\
\text { disorder }\end{array}$ & & & & 0.795 & & & & \\
\hline No & $352(70.3)$ & $121(36.3)$ & 1 & & & & & \\
\hline Yes & 148 (29.7) & $51(34.8)$ & $0.93(0.52-1.65)$ & & & & & \\
\hline
\end{tabular}

${ }^{a}$ Adjusted for age, marital status, highest level of education and number of clients in the last week 
HIV-positive status are more likely to transition into sex work, although we were not able to explore this in our survey data. A study among sex-workers attending a clinic in Kenya found that younger women were at higher risk of HIV infection, and that women in sex work for $<2$ years at enrolment had 2.3-fold higher risk of HIV than women in sex work for $>2$ years [23]. An earlier study in India among brothelbased sex-workers found that HIV prevalence was higher among sex-workers aged $\leq 20$ compared to sex-workers aged 21 or older (12.5\% vs 5.4\%) [24]. A better understanding of the complex relationship between HIV risk and entry into sex work is required to effectively target HIV prevention and social protection services based on the needs of different groups of women.

Despite our hypothesis that sexual risk behaviours would become less risky between 2013 and 2016, analysis of sexual behaviours found that sexual risky behaviours actually became more risky within this period, particularly among women who reported to be HIV negative. This upward change in some risky behaviours was also seen in Thailand among men who have sex with men, an equally most-atrisk population [25]. Condom-less sex with steady partners increased in 2016 compared to 2013 but the magnitude of increase was higher among women who reported being HIV negative compared to those who reported their HIV status as positive. This might suggest that women aware of their HIVpositive status may adopt safer behaviours to reduce the risk of onward transmission to clients and partners, and points to the need for additional targeting of HIV negative young women. Or possibly that more women have steady partners who are aware of their HIV negative status.

Both reported condom use at last sex and condom-less sex in the previous month with clients increased between 2013 and 2016, which is contradictory. Reported condom use is subject to social desirability bias, so while it is possible these changes may reflect changes in actual condom use they could also reflect biases in reporting. Poor validity of self-reported sexual behaviours, particularly condom use, is well recognised [26, 27], with condom use at last sex considered at particular risk of over-reporting [28]. Similar to studies among FSW in India [29] and Cambodia [30], our analysis of factors associated with prevalent HIV found no association between condom use variables and HIV. HIV may have been acquired some time prior to the survey. Further, women may or may not be using condoms because they know their HIV status and/or their partners' HIV status, or if they know that ART treatment is effective at preventing HIV transmission. Despite the complexities and limitations in understanding the relationship between recent condom use and prevalent HIV, reported condom-less sex in the past month was also high among HIV-negative young FSW. Although an important prevention tool, condom provision alone may be insufficient to protect young
FSW from HIV, particularly without specific interventions to increase risk perception and improve condom negotiation skills. In recent years, trials have proven the effectiveness of oral pre-exposure prophylaxis (PrEP) in reducing HIV among women adherent to PrEP [31, 32]. The availability of PrEP provides an important alternate prevention tool for women, and an opportunity to reduce HIV incidence among this population of women.

After adjusting for age at the time of the survey in 2016, lower educational attainment was strongly associated with HIV. This finding is similar to trends observed in some, but not all, sub-Saharan African countries [33]. Studies among young women in the general population have shown that staying in school can reduce HIV risk in some settings [34, 35 ] and that educational attainment has a protective effect against HIV [36, 37]. Low educational attainment has also been shown to be associated with initiating selling sex, likely contributing to increased HIV risk [5, 38]. Our findings emphasise the need to identify female adolescents who are at risk of dropping out of school to either support them to remain in school or provide a safety net to reduce their future vulnerability to HIV [39]. Interventions such as the DREAMS partnership which address the structural drivers of HIV are likely important for preventing HIV in this population [11].

Our study is subject to limitations. The women participating in the survey were recruited through RDS. Due to the nature of RDS, we cannot empirically explore whether the sample of women participating in the survey is representative of FSW in the study sites. However, extensive diagnostic testing of the RDS data suggests little evidence of bias [10, 19], although, as we have reported elsewhere, there is some suggestion that women who engaged with the Sisters with a Voice programme were more likely to participate in the 2016 survey [19] which might explain social desirability bias in reporting of condom use at last sex because women are taught about the importance of condom use at programme visit. The surveys were cross-sectional and therefore we cannot explore the temporal relationship between risk factors and HIV. The check identifier we used to minimise the risk of duplicate enrolment in each survey was subject to women using different names and/or giving different date of birth. However, many participants aged 22 to 24 in 2013 (43\%) would have aged out of eligibility by 2016 , and additionally those aged 18 to 20 in 2016 (23\%) would have been ineligible to take part in the 2013 survey. Despite these limitations, both surveys include a sizeable proportion of young FSW recruited using the same RDS procedures in 14 sites nationally. The findings provide critical insights into the vulnerability and HIV risk among this understudied population of women.

In conclusion, our findings confirm that young FSW in Zimbabwe are at a very high risk of HIV. The 
multicomponent DREAMS Partnership aims to reach YWSS, providing an important opportunity to offer these women a package of services to improve their health and well-being, tailored to address the findings from this research, such as condom negotiation, access to education, PrEP, and sexual and reproductive health services more generally. As part of DREAMS, PrEP is being offered to YWSS. To maximise the HIV prevention impact of PrEP, programmes will need to address structural factors such as costs and social factors such as stigma likely to hinder PrEP access and adherence among young FSW, which DREAMS partnership is designed to provide [11]. To support effective targeting of future strategies to reduce HIV risk, a better understanding of whether FSW's higher HIV risk is due to a high risk when they first initiate sex work, or reflects higher risk prior to transitioning into sex work, is needed. Such information would help identify strategies to target young women when they are most at risk of HIV, and refer them into appropriate socioeconomic services and HIV-prevention and related health interventions.

Acknowledgments We would like to thank CeSHHAR staff and peer educators who were involved in the SAPHH-IRe trial as well as the women who participated in the surveys.

Funding The SAPPH-Ire trial was funded by UNFPA via Zimbabwe's Integrated Support Programme which receives funds from DfID, Irish Aid and Swedish SIDA. A small amount of funding for survey work was from GIZ. USAID supported the cost of PSI Zimbabwe to provide ART and PrEP to sex workers as part of the trial. We received a donation of Truvada for PrEP use for the trial from Gilead. Data analyses for this manuscript was funded by the Bill and Melinda Gates Foundation (OPP1136774).

\section{Compliance with Ethical Standards}

Conflict of interest The authors declare that they have no conflict of interest.

Ethical Approval The SAPPH-IRe 2013 and 2016 surveys were reviewed and approved by the Medical Research Council of Zimbabwe, University College London, the London School of Hygiene and Tropical Medicine, and RTI International before the initiation of research activities. All procedures performed were in accordance with the ethical standards of the institutional and/or national research committee and with the 1964 Helsinki declaration and its later amendments or comparable ethical standards.

Informed Consent Informed consent was obtained from all individual participants included in the study.

OpenAccess This article is distributed under the terms of the Creative Commons Attribution 4.0 International License (http://creativeco mmons.org/licenses/by/4.0/), which permits unrestricted use, distribution, and reproduction in any medium, provided you give appropriate credit to the original author(s) and the source, provide a link to the Creative Commons license, and indicate if changes were made.

\section{References}

1. UNAIDS. Global AIDS update. Geneva: UNAIDS; 2016.

2. Inter-Agency Working Group on Key Populations. HIV and young key populations: technical briefs. Geneva: UNAIDS; 2015.

3. Busza J, Mtetwa S, Chirawu P, Cowan F. Triple jeopardy: adolescent experiences of sex work and migration in Zimbabwe. Health Place. 2014;28:85-91.

4. Busza J, Mtetwa S, Mapfumo R, Wong-Gruenwald R, Hanisch D, Cowan F. Underage and underserved: reaching young women who sell sex in Zimbabwe. AIDS Care. 2016.

5. UNAIDS. HIV and young people who sell sex: a technical brief. Geneva, Switzerland; 2014.

6. Napierala Mavedzenge S, Fearon E, Hargreaves J, Mushati P, Mtetwa S, Chiyaka T, et al., editors. Estimating engagement in HIV care among young female sex workers in Zimbabwe. IAS 2015; 2015; Vancouver, Canada.

7. Napierala S, Chabata ST, Fearon E, Hargreaves JR, Busza $\mathrm{J}$, Mushati P, et al. Engagement in HIV care among young female sex workers in Zimbabwe. J Aquir Immune Defic Syndr. 2018;79(3):358-66.

8. Oringanje C, Meremikwu MM, Eko H, Esu E, Meremikwu A, Ehiri JE. Interventions for preventing unintended pregnancies among adolescents. Cochrane Database Syst Rev. 2016;2:CD005215.

9. Hargreaves JR, Fearon E, Davey C, Phillips A, Cambiano V, Cowan FM. Statistical design and analysis plan for an impact evaluation of an HIV treatment and prevention intervention for female sex workers in Zimbabwe: a study protocol for a cluster randomised controlled trial. Trials. 2016;17:6

10. Cowan FM, Davey CB, Fearon E, Mushati P, Dirawo J, Cambiano $\mathrm{V}$, et al. The HIV care cascade among female sex workers in Zimbabwe: results of a population-based survey from the sisters antiretroviral therapy programme for prevention of HIV, an integrated response (SAPPH-IRe) trial. J Acquir Immune Defic Syndr. 2017;74(4):375-82.

11. Abdool Karim Q, Baxter C, Birx D. Prevention of HIV in adolescent girls and young women: key to an AIDS-free generation. J Acquir Immune Defic Syndr. 2017;75:S17-26.

12. Cowan FM, Mtetwa S, Davey C, Fearon E, Dirawo J, Wong-Gruenwald R, et al. Engagement with HIV prevention treatment and care among female sex workers in Zimbabwe: a respondent driven sampling survey. PLoS ONE. 2013;8(10):e77080.

13. Chingono R, Chibanda D, Chabata ST, Maringwa G, Mupambireyi Z, Simms V, et al., editors. Validation of the 8-item Shona Symptom Questionnaire, as a measure of common mental disorders in a population with high HIV prevalence in Zimbabwe. 13th International AIDSImpact Conference; 2017; Cape Town, South Africa.

14. Patel V, Simunyu E, Gwanzura F, Lewis G, Mann A. The Shona Symptom Questionnaire: the development of an indigenous measure of common mental disorders in Harare. Acta Psych Scand. 1997;95:469-75.

15. Chibanda D, Verhey R, Gibson LJ, Munetsi E, Machando D, Rusakaniko S, et al. Validation of screening tools for depression and anxiety disorders in a primary care population with high HIV prevalence in Zimbabwe. J Affect Disord. 2016;198:50-5.

16. White RG, Hakim AJ, Salganik MJ, Spiller MW, Johnston LG, Kerr L, et al. Strengthening the reporting of observational studies in epidemiology for respondent-driven sampling studies: \& "STROBE-RDS" statement. J Clin Epidemiol. 2015;68(12):1463-71.

17. Volz E, Heckathorn DD. Probability based estimation theory for respondent driven sampling. J Off Stat. 2008;24(1):79-97. 
18. Heckathorn DD. Extensions of respondent-driven sampling: analyzing continuous variables and controlling for differential recruitment. Sociol Methodol. 2007;37(1):151-207.

19. Cowan FM, Davey C, Fearon E, Mushati P, Dirawo J, Chabata ST, et al. Targeted combination prevention to support female sex workers in Zimbabwe accessing and adhering to antiretrovirals for treatment and prevention of HIV (SAPPH-IRe): a clusterrandomised trial. Lancet HIV. 2018;5(8):e417-26.

20. Cowan F, Pascoe SJS, Langhaug LF, Mavhu W, Chidiya S, Jaffar $\mathrm{S}$, et al. The Regai Dzive Shiri Project: results of a randomised trial of an HIV prevention intervention for Zimbabwean youth. AIDS. 2010;24:2541-2.

21. Zimbabwe National Statistics Agency and ICF International. 2016. Zimbabwe Demographic and Health Survey 2015: Final Report. Rockville, Maryland, USA: Zimbabwe National Statistics Agency (ZIMSTAT) and ICF International.

22. Hargreaves JR, Mtetwa S, Davey C, Dirawo J, Chidiya S, Benedikt C, et al. Cohort analysis of programme data to estimate HIV incidence and uptake of HIV-related services among female sex workers in Zimbabwe, 2009-14. J Acquir Immune Defic Syndr. 2016;72(1):e1-8.

23. McKinnon L, Izulla P, Nagelkerke N, Munyao J, Wanjiru T, Shaw S, et al. Risk factors for HIV acquisition in a prospective nairobi-based female sex worker cohort. AIDS Behav. 2015;19(12):2204-13.

24. Sarkar K, Bal B, Mukherjee R, Saha MK, Chakraborty S, Niyogi $\mathrm{SK}$, et al. Young age is a risk factor for HIV among female sex workers: an experience from India. J Infect. 2006;53(4):255-9.

25. van Griensven F, Varangrat A, Wimonsate W, Tanpradech $S$, Kladsawad K, Chemnasiri T, et al. Trends in HIV prevalence, estimated HIV incidence, and risk behavior among men who have sex with men in Bangkok, Thailand, 2003-2007. J Acquir Immune Defic Syndr. 2010;53(2):234-9.

26. Zenilman JM, Weisman CS, Rompalo AM, Ellish N, Upchurch DM, Hook EWI, et al. Condom use to prevent incident STDs: the validity of self-reported condom use. Sex Transm Dis. 1995;22(1):15-21.

27. Evans JL, Couture MC, Stein ES, Sansothy N, Maher L, Page K. Biomarker validation of recent unprotected sexual intercourse in a prospective study of young women engaged in sex work in Phnom Penh, Cambodia. Sex Transm Dis. 2013;40(6):462-8.

28. Liu H, Morisky DE, Lin X, Ma E, Jiang B, Yin Y. Bias in SelfReported Condom Use: Association Between Over-Reported Condom Use and Syphilis in a Three-Site Study in China. AIDS Behav. 2016;20(6):1343-52.
29. Medhi GK, Mahanta J, Paranjape RS, Adhikary R, Laskar N, Ngully P. Factors associated with HIV among female sex workers in a high HIV prevalent state of India. AIDS Care. 2012;24(3):369-76.

30. Ohshige K, Morio S, Mizushima S, Kitamura K, Tajima K, Suyama A, et al. Behavioural and serological human immunodeficiency virus risk factors among female commercial sex workers in Cambodia. Int J Epidemiol. 2000;29(2):344-54.

31. Baeten JM, Donnell D, Ndase P, Mugo NR, Campbell JD, Wangisi $\mathrm{J}$, et al. Antiretroviral prophylaxis for HIV prevention in heterosexual men and women. N Engl J Med. 2012;367(5):399-410.

32. Fonner VA, Dalglish SL, Kennedy CE, Baggaley R, O'Reilly KR, Koechlin FM, et al. Effectiveness and safety of oral HIV preexposure prophylaxis for all populations. AIDS. 2016;30(12):1973-83.

33. Hargreaves JR, Bonell CP, Boler T, Boccia D, Birdthistle I, Fletcher A, et al. Systematic review exploring time trends in the association between educational attainment and risk of HIV infection in sub-Saharan Africa. AIDS. 2008;22(3):403-14.

34. Handa S, Halpern CT, Pettifor A, Thirumurthy H. The Government of Kenya's Cash Transfer Program reduces the risk of sexual debut among young people age 15-25. PLoS ONE. 2014;9(1):e85473.

35. Stoner MCD, Pettifor A, Edwards JK, Aiello AE, Halpern CT, Julien A, et al. The effect of school attendance and school dropout on incident HIV and HSV-2 among young women in rural South Africa enrolled in HPTN 068. AIDS. 2017;31(15):2127-34.

36. Ramjee G, Daniels B. Women and HIV in Sub-Saharan Africa. AIDS Res Ther. 2013;10(1):30.

37. Pettifor AE, Levandowski BA, MacPhail C, Padian NS, Cohen MS, Rees HV. Keep them in school: the importance of education as a protective factor against HIV infection among young South African women. Int J Epidemiol. 2008;37(6):1266-73.

38. Bekker L-G, Hosek S. HIV and adolescents: focus on young key populations. J Int AIDS Soc. 2015;18(2 Suppl 1):20076.

39. Delany-Moretlwe S, Cowan FM, Busza J, Bolton-Moore C, Kelley K, Fairlie L. Providing comprehensive health services for young key populations: needs, barriers and gaps. J Int AIDS Soc. 2015;18(2 Suppl 1):19833.

Publisher's Note Springer Nature remains neutral with regard to jurisdictional claims in published maps and institutional affiliations. 